\title{
○䢸战的
}

\section{Ciência brasileira em crise: a ciência em rede como estratégia de enfrentamento}

\author{
Jacqueline Leta \\ Doutora; Universidade Federal do Rio de Janeiro, Rio de Janeiro, RJ, Brasil; \\ jleta@bioqmed.ufrj.br \\ Kizi Mendonça de Araújo \\ Doutora; Fundação Oswaldo Cruz, Manguinhos, RJ, Brasil; \\ kiziaraujo@yahoo.com.br \\ Vânia Lisboa da Silveira Guedes \\ Doutora; Universidade Federal do Rio de Janeiro, Rio de Janeiro, RJ, Brasil; \\ vanialisboa@facc.ufrj.br
}

Nas últimas duas décadas, o governo brasileiro implementou uma série de políticas visando ao fortalecimento e à expansão do setor de Ciência, Tecnologia e Inovação (CT\&I) no país. Essa nova fase, em certa medida, se contrasta com períodos anteriores, quando as instabilidades econômicas, que afetaram todo o país, dificultaram o avanço do setor. Um marco neste esforço recente foi a criação dos Fundos Setoriais de Ciência e Tecnologia, cujo objetivo era garantir recursos, de diferentes fontes, para o Fundo Nacional de Desenvolvimento Científico e Tecnológico (FNDCT). Muito embora os Fundos tenham sido criados em 1999, os recursos oriundos desta fonte só foram, efetivamente, alocados para o FNDCT em meados dos anos 2000, quando passaram de pouco mais de $\mathrm{R} \$ 340$ milhões em 2002 para $\mathrm{R}$ \$ 3,2 bilhões em 2010. Um exemplo de como esse recurso foi usado é mencionado na declaração do físico Sérgio Machado Rezende, quando ainda era ministro da pasta de ciência e tecnologia, que disse: "O Programa Espacial Brasileiro, por exemplo, em 2002, teve R\$ 70 milhões e agora, em 2010 teve R\$ 400 milhões"1.

Nos anos 2000, a expansão de financiamento público não ocorreu de forma isolada ou desconectada com as demais políticas governamentais. Na verdade, este período da história brasileira foi marcado pelo estabelecimento de diversas ações e pela elaboração de políticas que buscaram deslocar o papel do setor de CT\&I, colocando-o como um dos pilares para alavancar o desenvolvimento econômico e ampliar a inclusão social em nosso país. 


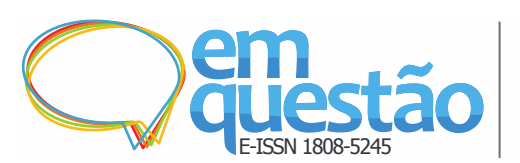

Ciência brasileira em crise: a ciência em rede como estratégia de enfrentamento

Jacqueline Leta, Kizi Mendonça de Araújo e Vânia Lisboa da Silveira Guedes

Dentre as iniciativas destacam-se as $2^{\mathrm{a}}, 3^{\mathrm{a}}$ e $4^{\mathrm{a}}$ Conferência Nacional de CT\&I, realizadas em 2001, 2005 e 2010, respectivamente, que representaram um espaço de ampla discussão entre os diferentes atores do sistema da CT\&I, inclusive os empresários, sobre as prioridades e as metas a serem atingidas para a efetiva consolidação do setor nas diversas áreas e regiões do país. Também se destaca o Plano de Ação em Ciência, Tecnologia e Inovação (PACTI) 2007-2010, anunciado em novembro de 2007, que se estrutura em quatro eixos prioritários: (a) a Expansão e Consolidação do Sistema Nacional de C,T\&I, (b) a Promoção da Inovação Tecnológica nas Empresas, (c) a Pesquisa, Desenvolvimento e Inovação em Áreas Estratégicas e (d) C,T\&I para o desenvolvimento social. Esse plano foi a base, em 2011, para a elaboração da Estratégia Nacional de Ciência, Tecnologia e Inovação (ENCTI), um novo plano para o setor que articula CT\&I com a política industrial brasileira. O ENCTI traz para a pauta ações que visavam estimular a inovação no país, como o fortalecimento da FINEP e a criação da Empresa Brasileira de Pesquisa e Inovação Industrial, cuja ideia central era promover uma maior interação entre universidades e empresas e outras ações que buscavam fomentar parcerias e colaborações internacionais, como o Programa Ciência sem Fronteiras. Neste contexto, ocorre a mudança de nome do Ministério da Ciência e Tecnologia (MCT) para Ministério da Ciência e Tecnologia e Inovação (MCTI).

Essas ações e tantas outras não citadas aqui criaram um ambiente favorável para a ampliação e diversificação do parque científico e tecnológico no Brasil, como também contribuíram para posicionar o país dentro do cenário internacional. Assistimos, assim, ações concretas que levaram a um crescimento de infraestrutura e de pessoal qualificado para setor de CT\&I nunca antes visto na história do país, em especial no sistema federal de pesquisa e ensino superior. Mais de uma dezena de novas universidades, centenas de novos campi universitários e uma extensa rede de institutos federais de educação, ciência e tecnologia foram criados não só nos grandes centros, mas sobretudo no interior do país. Movimento semelhante também ocorreu nos institutos de pesquisa federal que ampliaram sua infraestrutura e pessoal. Como consequência, o número de pesquisadores e docentes cresceu de forma excepcional, assim como o número de matrículas e bolsas na graduação e na pós-graduação. Tamanha expansão de recursos humanos em CT\&I impactou positivamente a produção científica brasileira, que chegou à posição $13^{\circ}$ no 


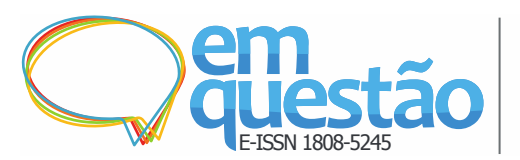

Ciência brasileira em crise: a ciência em rede como estratégia de enfrentamento

Jacqueline Leta, Kizi Mendonça de Araújo e Vânia Lisboa da Silveira Guedes

ranking de 25 países com maior número de publicações catalogadas pela, então, Thomson Reuters, no período 2008-2012.

A decisão de fomentar e ampliar o sistema CT\&I, para atuar como um dos atores centrais do desenvolvimento econômico e social e para tornar o país mais competitivo no cenário internacional, foi uma política continuada e crescente do Estado brasileiro, que ganhou destaque e ações efetivas a partir do final dos anos 2000. No entanto, a trajetória positiva em prol de um sistema de CT\&I forte e diverso foi interrompida com o golpe parlamentar de 2016. De fato, o projeto para o Estado brasileiro desenhado pelo governo interino retirou a CT\&I da sua agenda de prioridades. Isso fica claro quando consideramos tanto a reforma ministerial, como a implementação de medidas que visavam ao corte de despesas.

Realizada logo no início do governo interino, a reforma ministerial incluiu a fusão entre os ministérios da Ciência, Tecnologia e Inovação (MCTI) e das Comunicações. Essa medida gerou e gera, até hoje, muitas críticas da comunidade e das instituições científicas brasileiras que alegam, dentre outros aspectos, que tal junção representou um retrocesso histórico para o setor, ao retirar da CT\&I o papel de protagonista dentro das políticas de Estado. A repercussão desta fusão levou a Sociedade Brasileira para o Progresso da Ciência (SBPC) e outras 13 instituições do setor a assinarem conjuntamente um manifesto, em 2016, onde afirmam tratar-se de "uma medida artificial que prejudicaria o desenvolvimento científico, tecnológico e de inovação do País." 2

Muito embora os investimentos para CT\&I tenham sido reduzidos no período 2013-2015, observamos um queda ainda mais vertiginosa a partir de 2016, como resultado direto de medidas de contingenciamento embasadas na Ementa Constitucional 95/2016. Em 2017, após muita pressão da comunidade científica, o orçamento executado do MCTIC foi cerca de R \$ 4,6 bilhões, um valor que representou metade do orçamento executado em 2013! Ainda pior foi o orçamento de 2018 que caiu para R\$ 4,1 bilhões. Um cenário tão desolador que levou o Prof. Luiz Davidovich, presidente da Academia Brasileira de Ciência, a afirmar: "voltaremos ao status de colônia extrativista" 3 . 


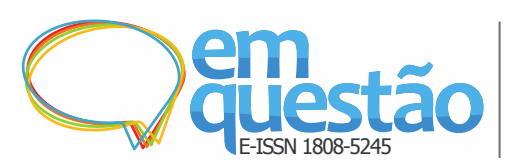

Ciência brasileira em crise: a ciência em rede como estratégia de enfrentamento

Jacqueline Leta, Kizi Mendonça de Araújo e Vânia Lisboa da Silveira Guedes

Os cortes também afetaram o orçamento das agências de fomento, sobretudo as federais, gerando grande insegurança em todos os atores do setor, principalmente nos bolsistas. Não menos importante foi o impacto destes cortes no setor da educação superior federal, um elemento chave no complexo sistema de CT\&I no Brasil, o que levou muitas universidades, institutos federais de educação e institutos de pesquisa a situações críticas, sem recursos para garantir o pagamento de despesas regulares, como energia elétrica. Por fim, vale lembrar dois exemplos que ilustram o impacto desta redução drástica dos investimentos para o setor: a extinção do programa Ciência sem Fronteiras e a retirada do país do Consórcio internacional de Astronomia, do Observatório Europeu do Sul (ESO), que não estava cumprindo com sua obrigação financeira.

A situação caótica e de deterioração dos setores de CT\&I e da Educação Superior levou a SBPC, em 2018, a lançar a Carta de Pernambuco, onde são listados 12 pontos que, segundo a Sociedade, são "essenciais para a reconstrução da ciência brasileira"4. Dentre estes pontos estão (a) a recriação do Ministério de Ciência, Tecnologia e Inovação, (b) a revogação da Ementa Constitucional 95 (a chamada Lei do Teto), (c) o fim do contingenciamento dos recursos FNDCT, (d) a recuperação dos valores investidos em CT\&I para próximo do valor investido em período 2009-2014, (e) o retorno do apoio e do fortalecimento dos programas e instrumentos essenciais à CT\&I, (f) a garantia do cumprimento dos acordos internacionais em andamento e (g) a elaboração de um novo Plano Nacional de CT\&I, apontando prioridades e metas.

É, portanto, dentro deste cenário de descontinuidade e também de extinção de programas e de ações voltadas para CT\&I, no qual o setor perde prestígio e prioridade nas políticas de Estado, que foi realizado em julho de 2018, na cidade do Rio de Janeiro, o $6^{\circ}$ Encontro Brasileiro de Bibliometria e Cientometria ( $6^{\circ}$ EBBC).

Entendendo a complexidade e o impacto negativo que o cenário político e econômico de 2018 imputava às atividades de CT\&I no país, a equipe de organização do $6^{\circ}$ EBBC elencou o tema "A Ciência em Rede" como eixo central das discussões, dada a sua relevância, atualidade e potencial estratégico. De fato, a ciência colaborativa, estruturada em grupos de pesquisa com número de integrantes cada vez maior, oriundos de instituições diversas, passou a ser uma das marcas da "grande ciência", tal como 


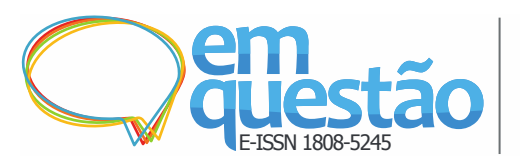

Ciência brasileira em crise: a ciência em rede como estratégia de enfrentamento

Jacqueline Leta, Kizi Mendonça de Araújo e Vânia Lisboa da Silveira Guedes

apontado por Derek de Solla Price, em sua clássica obra Little Science, Big Science, escrita em 1963.

Muitos são os fatores que levam os cientistas, as instituições e as nações a buscarem a colaboração na ciência, dentre eles, o compartilhamento de conhecimento ou de infraestrutura, a qualificação de pessoal e a redução de custos com equipamentos. Independente das razões, a literatura mundial indica claramente um movimento global contínuo e crescente no sentindo do estabelecimento de equipes multidisciplinares e, muitas vezes, multi-institucionais, bem como, o estímulo à formação de parcerias e articulações em rede, com vista a otimizar o processo de produção de conhecimento.

Neste contexto, a internet e as redes sociais emergem com o potencial de estreitar os laços entre os cientistas, diminuindo as barreiras geográficas e trazendo uma nova dinâmica à estrutura científica que, cada vez mais, se desenha como um sistema integrado e cooperativo, uma rede de conexões. O caso Zika vírus e sua relação com microcefalia é um exemplo atual e emblemático de como a ciência articulada em rede pode atuar de forma rápida e eficiente para a resolução de um problema.

Para tratar do tema "A Ciência em Rede", o $6^{\circ}$ EBBC contou com a participação de três convidados internacionais. Cassidy R. Sugimoto, da Universidade de Indiana, nos EUA, que proferiu a palestra de abertura intitulada Ciência em uma sociedade global: oportunidades e disparidades. Cameron Neylon, da Universidade de Curtin, na Austrália, e Stefanie Haustein, da Universidade de Ottawa, no Canada, deram voz à mesa intitulada Ciência em rede: cientistas e o impacto das mídias sociais. Além destes, outros dois convidados nacionais, Jesus Mena Chalco, da Universidade Federal do ABC, e Rita Barradas Barata, da Faculdade de Ciências Médicas da Santa Casa de São Paulo, finalizaram as reflexões do $6^{\circ} \mathrm{EBBC}$ na mesa intitulada Ciência em rede nos países periféricos.

Ao longo do evento, os 198 participantes tiveram contato com o conceito de Ciência em rede (ou a Colaboração na ciência) em vários momentos, em especial na sessão 1C, onde todas as seis apresentações, em formato de comunicação oral, abordaram o tema. Já para a chamada do número especial da Em Questão, 32 trabalhos foram submetidos e, após um intenso processo de revisão por pares, 15 deles foram aprovados. Destes, pelo menos quatro focam e/ou discutem mais diretamente questões 


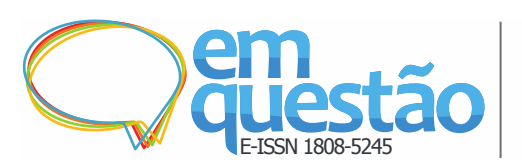

Ciência brasileira em crise: a ciência em rede como estratégia de enfrentamento

Jacqueline Leta, Kizi Mendonça de Araújo e Vânia Lisboa da Silveira Guedes

acerca dos conceitos de rede ou colaboração na ciência, enquanto os demais têm ênfase em outros temas, igualmente atuais e relevantes.

Entendemos que o conjunto de trabalhos selecionados para este número especial ajuda a conhecer melhor a produção científica brasileira assim como oferece perspectivas teóricas e metodológicas de grande relevância para o fortalecimento das áreas de Bibliometria e de Cientometria no país, uma vez que discute temas inovadores, como a produção científica em rede em diferentes áreas do conhecimento científico e tecnológico. Por fim, reiteramos a importância estratégica de pensar a ciência em rede como uma estratégia para o enfrentamento da crise instalada, de modo a manter viva a ciência brasileira.

Desejamos a todos uma ótima leitura! Jacqueline Leta, Kizi Mendonça de Araújo \& Vânia Lisboa da Silveira Guedes

\footnotetext{
${ }^{1}$ https://www.redebrasilatual.com.br/tecnologia/2011/01/ex-ministro-diz-que-era-lula-foi-o-melhor-momento-da-ciencia-e-tecnologia-no-brasil

2 http://www.sbpcnet.org.br/site/artigos-e-manifestos/detalhe.php?p=5079

3 https://netnature.wordpress.com/2018/11/21/pec-do-teto-esta-sufocando-a-ciencia-brasileira/

${ }^{4}$ http://portal.sbpcnet.org.br/noticias/carta-de-pernambuco-politicas-publicas-para-o-brasil-que-queremos/
} 